\title{
Critical Media Literacy for Elementary Students in an After-School Programme
}

\author{
Angela M. Wiseman, Melissa Wrenn
}

\begin{abstract}
As students' uses and experiences with literacy are changing due to technological innovations, particularly in their out-of-school contexts, it is important to consider how media literacy is a social practice, particularly one where students are engaging socially, culturally, and politically. This is particularly relevant to the way that messages are conveyed through popular media such as commercials, video games, and television programmes. The purpose of this paper is to explore what happens when students use a critical media literacy to respond to mass media texts and images. The primary question this research attempts to answer is: What happens when students use a critical media literacy approach to discuss and interpret print and visual media images in an after-school setting? We used qualitative research methods to collect data and thematic analysis to analyse data. Findings reflect how students discussed identity, bullying and aggression, socioeconomic status, materialism and consumerism.
\end{abstract}

Keywords: critical media literacy, elementary students, qualitative research.

\section{INTRODUCTION}

Technology has dramatically transformed the way that children are exposed to information and communicate ideas. Children are growing up exposed to multimedia, and information is more likely to be transmitted through visual images, sounds, and other forms of technology rather than traditional print sources. Digital texts, posts, feeds, and other forms of communication are central to young people as they increasingly turn to digital culture and social media (Funk, Kellner, \& Share, 2015; Puchner, Markowitz, \& Hedley, 2015). As a result, it is important to con- sider how media literacy is a social practice, particularly one where students are engaging in social, cultural, and political ways (Livingstone et al., 2012).

Children's increased exposure to media and technology necessitates an understanding of how it affects their thinking about political, economic, historical, and social contexts (Kellner \& Share, 2007; Kelly \& Brower, 2017). A critical media literacy approach encourages students and teachers to learn using new modes of communication and popular culture so they can critically read media texts and build understanding of the political, cultural, economic, historical, and social contexts 
of the messages (Flores-Koulish \& SmithD'Arezzo, 2016; Kellner \& Share, 2007; Tobin, 2000). This is particularly the case with media such as television shows, advertisements, and commercials, which sometimes can reflect normative ways of representing critical social issues. Integrating critical media literacy into educational contexts builds on the complex process of synthesising and inferring meanings alongside exploring representation of race, class, gender, and identity. Specifically, as children engage with images and ideas through technology, educators can play an important role in teaching them how to consider messages and ideas they engage with from a critical standpoint.

This paper reports findings from a critical media literacy project conducted with a group of students, ages 8-11, in an after-school programme. We used qualitative research methods to collect data and thematic analysis to discover findings. The primary question this research attempts to answer is: What happens when students use a critical media literacy approach to discuss and interpret print and visual media images in an after-school setting?

\section{Theoretical Framework AND Related RESEARCH}

\section{Critical Media Literacy}

Critical media literacy focuses on the ideological factors of texts, readers, and power and can be defined as "an educational response that expands the notion of literacy to include different forms of mass communication, popular culture, and new technologies" (Kellner \& Share, 2007, p. 60). No texts are neutral; therefore, children need tools to consider how they make meaning and use multiple texts (Kessler, Tinio, \& Nolan, 2016). As educators, we recognise the need to explore how children respond to media literacy from a critical standpoint, yet exploring views about identity are complex and messy, often creating conversations or responses that challenge the teachers' intentions. From a pedagogical perspective, critical media literacy provides a framework for exploring the images and content with which children engage as they explore and create using technology and media. Taking a critical stance with media that children engage with outside of school could have a transformational potential and may possibly create a different learning dynamic in the classroom.

As children critically analyse media, they can engage, resist, and critique dominant discourses (Gainer, 2010; Silverblatt et al., 2014; Tobin, 2000). This process of questioning and examining issues can serve an important function of encouraging students to consider their own understandings and reflect on how the media influences their worldviews. The insight gained from analysing students' responses to media texts provides a way of understanding their own identities and assumptions. For example, Medina and Costa (2013) observed third grade students living in Puerto Rico as they designed and enacted their own 'telenovelas' (popular Latino/a melodramas). Students' redesigns of the dramas allowed them to explore power dynamics related to appear- 
ance, class, gender, childhood and relationships. Marsh and Bishop (2014) documented the strong influence that media has on children's informal play at school and observed how children's re-enactment of a popular TV show allowed them to explore contested norms, including ethical issues and social class. Using the abundance of digital technologies and multimodal experiences in pupils' out-of-school lives, critical media literacy encourages children to make sense of how racism, sexism, classism, and other prejudices are embedded in media texts.

Children's media practices can provide an important springboard for discussing important and relevant issues as well as connecting with strategies related to critical thinking, reading, and writing (Bazalgette \& Buckingham, 2013; Marsh \& Bishop, 2014; Marsh, 2014; Puchner et al., 2015). This is particularly relevant for young children and should be incorporated in the primary curriculum since media use occurs at a very young age. Bazalgette, Parry, and Potter (2011) synthesised research from several studies which demonstrated how children explored complex concepts about how media texts were created as early as age 3, demonstrating sophisticated responses important ideas and topics.

\section{Methodology}

\section{Context}

This study takes place in an after-school programme for children ages 6-14 years that is located in a large southeastern city in the United States. On a weekly basis, children are transported to a nearby university media centre with undergraduate volunteers there who read with students and engage in technology projects. This partnership has been developed as a connection between faculty, students, and community members.

A selected group of students were identified jointly with Angela and Edmond, the director of the after-school programme to participate in a critical media literacy programme. The participants are as follows: Hector is a 10 years old, $5^{\text {th }}$ grader, who is Hispanic. He reported that he does not read or use a computer daily. Much of his technology use was affected by his family's income level because they did not have a computer and "lost the cable" to their television. His family did, however, use their smartphones to watch videos, and he also used an app called "Vine" to look at pictures or text his sister who is 12 . Hector also reportedly uses Twitter, email, and Facebook through his parents' accounts. $\mathrm{He}$ plays video games regularly, including Call of Duty Black Ops 2, Halo Reach, World at War, and Modern Warfare 2 and 3. Juanita is an 11 years old Hispanic $5^{\text {th }}$ grader. She is an avid reader who spends more time on books than the computer, but she does play games or watch music videos on the computer daily. She also watches TV, particularly Spanish shows, on a daily basis. She does not play video games on a console, but does play games on the iPad such as Subway Surfers. Isabel is a 9 years old girl with both an African-American and Hispanic background. She reported that she read an hour a day but did not use the computer. However, she did report that she uses an iPad daily 
and watches an episode of television as part of her evening routine. Brad reported that he reads for many hours each day, especially comic books. He does play video games, both on the computer and on electronic devices, daily. He also watches TV regularly.

\section{Critical Media Literacy Programme}

Students participated in ten sessions where they explored, analysed, and designed as they responded to TV shows, video games, print ads, and texts. As researchers taking a critical approach to literacy practices, we began with the assumption that all texts held values and privilege some perspectives and identities (Marsh \& Bishop, 2012; Semali, 2003). We started with a usage survey to find out the video games, movies, TV shows, and other forms of media they were watching. In addition, we also knew of their experiences and interests from prior interactions with them in the after-school programme.
Angela and Melissa developed critical media lessons, influenced by Tobin's (2000) practices for engaging children in conversations about popular media (for more about the lessons, see Wiseman, Kupiainen, \& Makinen, 2017). We were also informed by pedagogical approaches to critical media literacy and sought to include opportunities for students to critique representations of gender, race, class, and sexuality (Funk et al., 2015; Kellner \& Share, 2007). During each lesson (see Appendix), we posed questions designed to encourage students to consider or question power relationships in the texts. We encouraged collaborative discussion among students and let them guide conversations, asking questions to encourage students to consider how they identified with the texts. Finally, we created opportunities for students to analyse the texts in terms of their practical applications (e.g., target audience, purpose). Table 1 describes our framework and provides some examples of guiding questions.

Table 1. Critical Media Literacy Components and Guiding Questions (Kellner \& Share, 2007; Tobin, 2000)

\begin{tabular}{|l|l|}
\hline Components & Guiding Questions \\
\hline Questioning Power & $\begin{array}{l}\text { Can girls and boys engage with this idea or item? How are the } \\
\text { most powerful people depicted? Why? Who are not depicted } \\
\text { as powerful? Why? }\end{array}$ \\
\hline Collaborative Discussion & $\begin{array}{l}\text { How are you making meaning together? } \\
\text { How are you learning from each other? }\end{array}$ \\
\hline Identity enactment or change & $\begin{array}{l}\text { Are any of the people in the media like you? Which one(s)? } \\
\text { Why? }\end{array}$ \\
\hline $\begin{array}{l}\text { Reading/viewing of } \\
\text { popular media }\end{array}$ & $\begin{array}{l}\text { Who is the target audience for this image or video? How do } \\
\text { these images make you feel? }\end{array}$ \\
\hline
\end{tabular}


Fieldnotes were taken at each session by Angela and Melissa and were reviewed to determine what topics were relevant and significant in order to design the next discussion. After identifying relevant topics, we selected media from the students' everyday lives and paired children's literature that explored connecting topics. In this way, the discussions were iterative and responsive to important themes and issues that emerged from the students' conversations. For example, in Lesson 1 we discussed excerpts from a book called Families (Kuklin, 2006), a book that depicts a diverse range of families based on race, class, and sexuality. During this discussion, we noted that they demonstrated interests in families, culture, and diversity. In Lesson 2, students continued to make comments about families, particularly focusing on the idea that various caregivers can make a family. As a result, Angela and Melissa decided to design Lesson 3 around a brief clip from a popular Disney show, Jessie (we knew from the survey that many of the children had watched Disney shows, when we showed them the clip, some had already seen it), and re-read parts of the book Families (Kuklin, 2006); both depicted either multiracial families and/or different caregivers who raised children.

\section{Redesign}

During the last two class sessions, we encouraged the children to engage in the process of product or image redesign. The emphasis was on creating a product that provided a certain message to an audi- ence. While the sessions covered a broad range of topics such as diverse families, socio-economic status, poverty, violence, bullying, and gender, the students focused on two topics for their redesign: gender representation and poverty. At the conclusion of the study, students presented their redesigned products to one another. After the redesign presentations, students participated in an interview process to debrief about their experiences. Throughout the process of engaging students in the lessons and the final redesign, Angela and Melissa asked open-ended questions designed to understand more about how students critically engaged in discussions of the texts.

\section{Data Collection and Analysis}

To determine how students used a critical media literacy approach to discuss and interpret print and visual media images, we began by analysing and coding topics that emerged from their conversations and artifacts. We used inductive methods to develop thematic categories (Creswell $\&$ Poth, 2018). There were four themes that emerged from this analysis; (1) identity related to race, gender, or appearance, (2) bullying and aggression, (3) socioeconomic status, and (4) materialism and consumerism.

Ensuring trustworthiness through credibility, transferability, dependability, and confirmability was an important part of our research design (Merriam, 2009). By having prolonged involvement in this after-school programme (this was the 
third year that Angela had volunteered with these students), collaboration with research participants, and varied types of data, we ensured credibility. The research was transferable through thick description and understanding of the context (Merriam, 2009; Tracy, 2010). The data were confirmed using methods of triangulation, particularly through the use of multiple data sources such as students' interviews, transcripts from group discussions, and culminating redesigns (Creswell \& Poth, 2018).

\section{Findings}

In this section, we present our findings thematically. Our findings illustrate that students discussed identity, bullying and aggression, socio-economic status, materialism and consumerism.

\section{Identity Related to Race, Gender, and Appearance}

Race, gender, and appearance were prevalent topics in students' responses to media texts. Students often discussed and even debated differing expectations for girls and boys. For example, three of the students incorporating their ideas about gender as they critiqued and redesigned commercials and products. For instance, when Hector shared his revisioning of Call of Duty with the group (see Figure 1), we saw intersections of gender with video game design.

Hector: Well, I wanted to like make a new video game cause like some ones they don't have like a lot of you have to like use the internet to get the special bonuses and everything. So I made this game, Call of Duty: Infection, so you can like do whatever you want like play some like maps and some or like download them. And then you can you can make like everything like your own person and place and even like your story.

Melissa: How is this different from the other Call of Duties? Like here [pointing to the plan he created for his redesign]. You said it's for boys and girls, can you talk about that a little bit?

Hector: Because in a lot of other Call of Duties it's only for boys because most of the girls don't like violence.

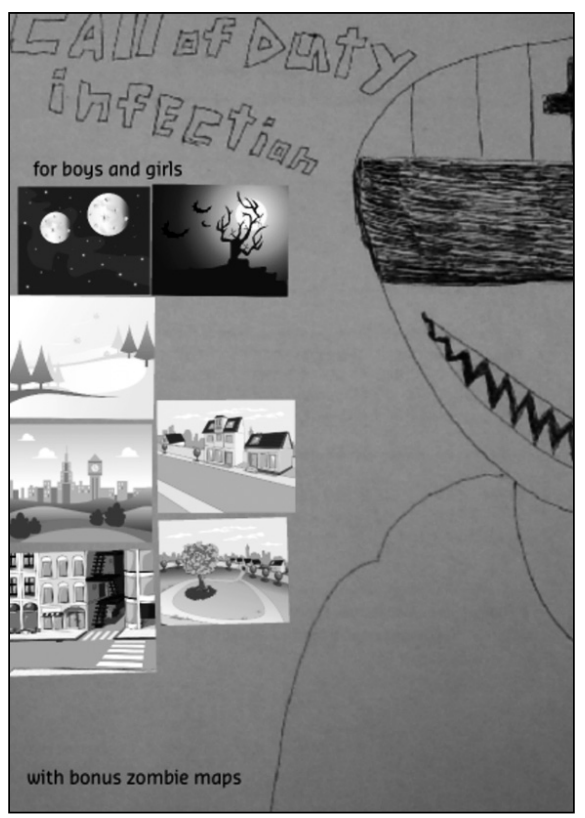

Figure 1. Hector's redesign for gender 


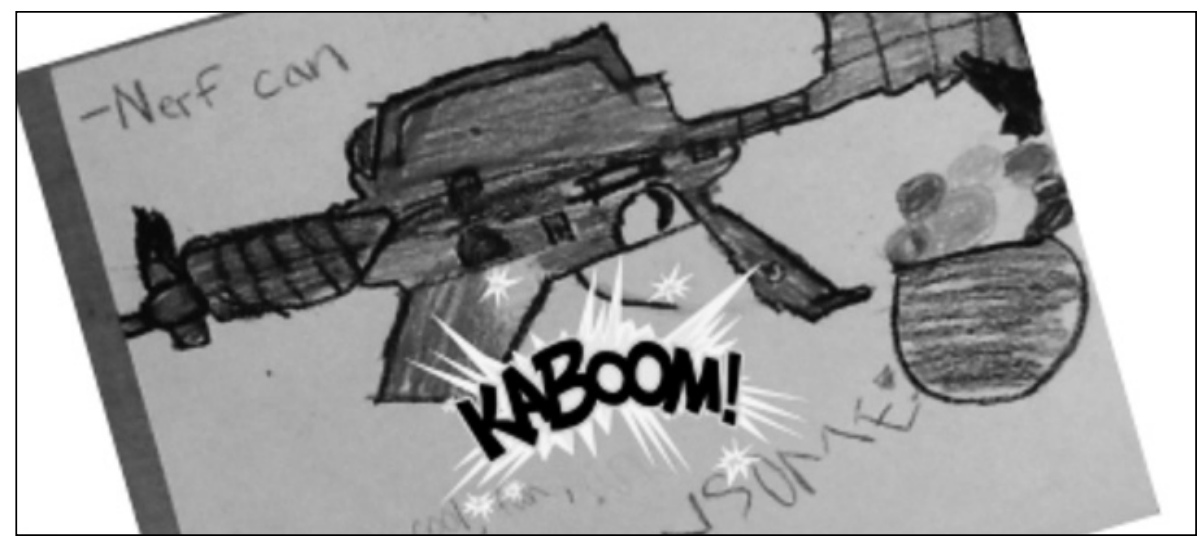

Figure 2. Juanita's redesign for gender

During the redesign, Hector had the opportunity to revision Call of Duty to be, per his description, "more appealing to girls", whom he believed would not like violence. The premise of his game was fighting a zombie infection rather than the game's original intention of warfare. There is no indication that Hector was aware that his redesign and movement toward creating a gender-neutral product also reduced the violence toward humans, yet he did recognise that his version was less violent. This response still left us wondering about some of the conversations we had about race and gender and demonstrated the complexities of students' ideas about gender and identity.

As the children were redesigning products, we saw more evidence of exploring the impact of gender on product design. In this exchange, Juanita explains her product and describes how she wanted to create something that was not targeted specifically for boys or girls, but would be marketed for both (see Figure 2). She explained that, "My design is about the Nerf toys... I wanted to make something new for boys and girls... I designed a gun and some paintballs and they can be any colour and they can be black and red and any colour you want..." In her explanation, she covered two important ideas. First, she was addressing the idea that toys do not need to be marketed for boys or girls and that she could design something that would be for both. Juanita was also exploring the idea of encouraging any child to select a colour based on preference, which would not necessarily have to be associated with gender binaries.

\section{"Being a Bystander and Helping People": Bullying and Aggression}

We found that bullying and aggression were topics that came up repeatedly as they described aggressive language, bully- 
ing, cyberbullying, and video games. Our selection of television shows and commercials included topics that were appropriate for their age group and could be shown in school (but we learned that students had seen movies that were geared to adults). Despite the fact that we chose texts that only had very mild forms of aggression, students recognised subtle and overt aggression and made very personal connections to the texts we reviewed. Their conversations described their own exposure to violent shows and video games that they viewed at home. For instance, in one conversation where students were looking at advertisements, they started talking about video games. Hector describes a game, explaining that, in "Call of Duty Ghost they have like aliens and you have to like kill them. Because they're like this [inaudible] or something that you have to put in front and it like kills it... It's called drill. You have to protect it from aliens."

From other conversations, we also realised that bullying was an important topic, so we decided to select clips from TV shows and texts where we could explore this topic. We selected a clip from the show "Recess," where a main character was bullied by his classmates on the playground because we knew that many of the students watched Disney cartoons. Students were particularly interested in the roles of bystanders and how to stand up to bullies. Juanita recognised that the clip could empower others to think about what they could do if they saw an incident.

Juanita: Probably they made this clip for like the kids to like if they're a bystander and can help people. And like the kids don't bully who are watching it. They can stop bullying because they can, so they can they don't want people to be mean to them and stand up for themselves probably.

Juanita often mentioned the role of bystanders in bullying, and she recognised that the show may inspire others to stop bullying. Her comment reflected the understanding that bystanders serve an important role in aggression towards others.

\section{"What Does it Mean if a Person is Rich or Poor?": Explorations of Socio-economic Class}

Socio-economic status was a significant theme in student discussions, often explored through intertextual connections where students made connections across books they read in class or movies they had watched out of school. For instance, during an 'ad sort' as the students evaluated products based on certain attributes, Hector and Brad discussed what it meant to be rich or poor. At this time, Brad brought up the connection of bullying and poverty from The Watson's Go to Birmingham (Curtis, 1995) while the students were engaging in a conversation about ads that appeared in magazines.

Melissa: What does it mean if a person is rich or poor?

Hector: ... to be poor, you're losing all your money like your house and clothes and stuff.

Brad: To be poor you have bad clothes. Cause at school we were reading The Watson's Go to Birmingham, and it talks about 
this kid that he's getting picked on for not having that much clothes because he moved and they wouldn't accept the money that he had. Because it's Kansas money and it was a different kind and he and his brother switch blue jeans over and over again.

While we noted that Brad articulated a negative connotation that the poor have "bad clothes" (and this emanated from feeling like his own clothes were sometimes "bad"), Brad's redesign reflected themes of socio-economic status and poverty and an awareness of how it affected children in school. His product was a video game that was free of charge, as opposed to the expensive video games he sees in the gaming stores. Additionally, the plot of his redesigned video game included a character who would help the poor and even steal from the rich to give to the poor. $\mathrm{He}$ explained the basic plot of his video game to the group, saying:

Brad: You're the person who protects the poor and basically there are different modes where you can help out the poor and find these superpowers and help people out in the city. Then, there's like a mode where you can do whatever you want and fight bad people and spawn them in if you want to.

The main character of the video game had swords that would fight for the poor and he defined the "bad people" as the rich. Through both their comments to texts and their product redesigns, the students explored their perceptions of social class division in media.

\section{“That Makes Me Want to Buy It": Materialism and Consumerism}

Consumerism and materialism are implicitly linked to media (Livingstone et al., 2011; Kellner \& Share, 2007) and this topic is linked to our previous category of socioeconomic class. One component of our lessons entailed analysing products; evaluating the effectiveness, cost, product applications, and their access to products. Students' ideas about these concepts reflected deep thinking about these topics. For example, in discussions, Hector shared insightful ideas about the purposes of advertising, particularly the ads situated in websites he views. An example is when he said, "...some kids they like go on Youtube and they watch the video, you see some commercials in them, it's like they like they make you do something or buy something."

When discussing various products, students expressed that they often wanted things that their family could not afford. In the following excerpt, Juanita and Isabel discussed American Girl dolls during an activity where they reviewed and analysed advertisements. Juanita wanted one, but they were too expensive. Isabel, who owned an American Girl doll, disagreed because her mother was "not rich."

Angela: Juanita, why did you say it was for rich?

Juanita: Because I've seen the commercial and they look like they are all rich people.

Isabel: You pay attention to the commercials?

Juanita: Plus I wanted one, but my parents couldn't afford it. 
In both Hector's comment and the discussion of the American Girl doll ad, students indicate an awareness of the role of media in advertising. Juanita felt that the people in American Girl doll commercials "look like they are all rich," and she knew that it was too expensive for her family. Juanita determined the product was for "rich people" based upon how the children in the ad were dressed. When Isabel questioned Juanita further, she added a comment about her personal experience with the product.

Researchers have connected the increased viewing of media images with an increase in the way that advertisements and media images can convince students they need new and more desirable items (Levin, 2010). Children, from an early age, are exposed to commercials and ads that attempt to convince them that they "need" a certain product or that one product will create a type of lifestyle or experience. Often children (and adults) watch the descriptions of products passively without evaluating whether the information and images they impart are valid and relevant to their lives.

\section{IMPLICATIONS}

When students engage in reading, writing, speaking, listening with technology and texts, they are interacting in complex ways with literacy (Walsh, 2008). It is an important aspect of this work to use this knowledge to navigate inclusive ways of learning and representing that embrace the diverse perspectives found in our $21^{\text {st }}$ century classrooms. Teachers planning to implement critical media lessons in elementary classrooms should consider several key factors:

- Students may share sensitive, personal information during critical media literacy discussions. For example, students in this study shared information about their family dynamics and socio-economic status as they discussed media texts. Teachers can prepare for this situation by creating a classroom context that is sensitive to students and inclusive, as was the case with the after-school programme. Throughout the lesson, students shared their own experiences with issues such as poverty, school violence, or family stress.

- It is important for students to have the opportunity to explore critical issues. We propose that teachers take the role of selecting engaging texts and posing openended, purposeful questions that will allow students to explore the issues. This occurred in our study around the topic of gender issues. Our stance was not to suggest that students alter their views, but to encourage students to speak freely and respond to each other. A respectful environment was maintained and the adults acted as facilitators.

- We also recommend an iterative design for exploring issues in the classroom. Students' responses can provide insight on their concerns and experiences. Incorporating various media can provide important segues to relevant topics as well as multiple perspectives for students to consider. 
Critical media literacy can provide integration and acknowledgement of students' identities in educational contexts and the classroom curriculum. Moje (2009) proposes that identity work creates more active learning; when students have the opportunity to explore their identities through popular culture and new technologies, it provides them with the opportunity to engage more deeply with learning and meaning-making.
We end this article by stating that our findings demonstrate complexities in discussing difficult topics with students. While we saw that they were exploring different perspectives, we wonder how to discuss these topics in ways that may affect their actions and long-term world views. Moving forward, we believe that teachers should also reflect critically on their own practices and consider how their students are engaging with sensitive topics.

\section{References}

Bazalgette, C., \& Buckingham, D. (2013). Literacy, media and multimodality: a critical response. Literacy, 47(2), 95-102.

Bazalgette, C., Parry, B., \& Potter, J. (2011). Creative, cultural and critical: Media literacy theory in the primary classroom. In Creative Engagements: Thinking with Children 7th Global Conference. Oxford, UK. Available at http://eprints.whiterose.ac.uk

Creswell, J. W., \& Poth, C. N (2018). Qualitative inquiry and research design: Choosing among five approaches (4th edition). Los Angeles, CA: Sage.

Curtis, C. P. (1995). Watsons go to Birmingham. New York: Random House.

Flores-Koulish, S. A., \& Smith-D’Arezzo, W. M. (2016). "The Three Pigs": Can they blow us into critical media literacy old school style? Journal of Research in Childhood Education, 30(3), 349-360.

Funk, S., Kellner, D., \& Share, J. (2015). Critical media literacy as transformative pedagogy. In M. N. Yildiz \& J. Keengwe (Eds.), Handbook of research on media literacy in the digital age (Chapter 1). Hersley, PA: IGI Global.

Gainer, J. S. (2010). Critical media literacy in middle school: Exploring the politics of representation. Journal of Adolescent and Adult Literacy, 53(5), 364-373.

Kellner, D., \& Share, J. (2007). Critical media literacy is not an option. Learning Inquiry, 1(1), 59-69. Kelly, C., \& Brower, C. (2017). Making meaning through media: Scaffolding academic and critical media literacy with texts about schooling. Journal of Adolescent and Adult Literacy, 60(6), 655-666.

Kessler, T., Tinio, P. L., \& Nolan, B. T. (2016). What's our position? A critical media literacy study of popular culture websites with Eighth-grade special education students. Reading \& Writing Quarterly, 32(1), 1-26.

Kuklin, S. (2006). Families. New York: Hyperion.

Lee, R. (Director). (2011). 21st century girl [Recorded by Willow Smith]. Roc Nation, LLC [video]. Available at http://www.youtube.com

Levin, D. (2010). Remote control childhood: Combating the hazards of media culture in schools. New Horizons in Education, 58(3), 14-25. 
Livingstone, S., Papaioannou, T., Pérez, M. M. G., \& Wijnen, C. W. (2012). Critical insights in European media literacy research and policy. Media Studies, 3(6), 2-12.

Livingstone, S., Haddon, L., Görzig, A., \& Ólafsson, K. (2011). Risks and safety on the Internet: The perspective of European children. London: LSE, EU Kids Online. Available at http://eprints.lse.ac.uk Marsh, J. (2014). Purposes for literacy in children's use of the online virtual world Club Penguin. Journal of Research in Reading, 37(2), 179-195.

Marsh, J., \& Bishop, J. (2014). We're playing Jeremy Kyle! Television talk shows in the playground. Discourse: Studies in the Cultural Politics of Education, 35(1), 16-30.

Medina, C. L., \& Costa, M. del R. (2013). Latino media and critical pedagogies. Journal of Language $\&$ Literacy Education, 9(1), 161-184. Available at http://jolle.coe.uga.edu

Merriam, S. B. (2009). Qualitative research: A guide to design and implementation. San Francisco, CA: Jossey-Bass.

Moje, E. B. (2009). Standpoints: A call for new research on new and multi-literacies. Research in the Teaching of English, 43(4), 348-362.

Puchner, L., Markowitz, L., \& Hedley, M. (2015). Critical media literacy and gender: Teaching middle school students about gender stereotypes and occupations. Journal of Media Literacy Education, 7(2), 23-34. Available at https://digitalcommons.uri.edu

Semali, L. (2003). Ways with visual languages: Making the case for critical media literacy. The Clearing House, 76(6), 271-277.

Silverblatt, A., Miller, D. C., Smith, J., \& Brown, N. (2014). Media literacy: Keys to interpreting media messages (4th ed.). ABC-CLIO, LLC.

Tobin, J. (2000). "Good guys don't wear hats": Children's talk about the media. New York: Columbia University, Teachers College Press.

Tracy, S. J. (2010). Qualitative quality: Eight a "big-tent" criteria for excellent qualitative research. Qualitative Inquiry, 16(10), 837-851.

Walsh, M. (2008). Worlds have collided and modes have merged: Classroom evidence of changed literacy practices. Literacy, 42(2), 101-108.

Wiseman, A. M., Kupiainen, R., \& Makinen, M. (2017). Talking back and redesigning texts: Critical media literacy for elementary students in an afterschool program. In M. Bock, A. Hudelist, $\&$ F. Auernig (Eds.), Literacy in the new landscape of communication: Research, education and the everyday (p. 49-56). Graz, Austria: Austrian Literacy Association.

Angela M. Wiseman (USA), North Carolina State University;

e-mail:amwisema@ncsu.edu

Melissa Wrenn (USA), East Carolina University;

e-mail:wrennm18@ecu.edu 


\section{Appendix}

Lesson Plan

\section{Objective}

Students will begin to critically consider how boys and girls are treated in the media.

\section{Show students the print advert}

http://bigotedeleche.com/celebridades/herencia_hispana

\section{Activities}

1. Explain to students that ads are a persuasive text that are usually targeted to a specific audience.

a. Ask: What is this ad trying to sell? Who is the target audience?

b. How do you know?

2. Ask students to describe the people in the ad.

Complete a chart documenting their responses.

3. Group similarities and differences in the chart.

4. Ask: What do you notice? Who is the most powerful person in the ad? How does this ad make you feel? Are any of the people in the ad like you? Which one(s)? Why?

\section{Show video clips to students}

http://www.youtube.com/watch?v=Q0d3Xq-yXn4

1. Ask: What is this ad trying to sell? Who is the target audience? How do you know?

2. Can girls and boys play with this toy?

3. Ask students to describe the people in the ad.

Complete a chart documenting their responses.

4. Watch the second clip.

http://www.youtube.com/watch?feature=player_embedded $\& v=H 3 A m P-c H d 0 k \# t=17$

5. Ask: What is this ad trying to sell? Who is the target audience? How do you know? Can girls and boys play with this toy?

6. Ask students to describe the people.

\section{Looking Across Nerf Clips}

1. What do you notice?

2. Which ad shows people that are more like you? Why?

3. Which is the best ad? Why?

4. Which ad shows the most powerful people? Why? 


\section{Read texts}

Funke, C. (2001). The princess knight. United Kingdom: The Chicken House.

1. What did you think about the book?

2. How did the book make you feel?

3. Who was the most powerful person in the book? Why?

4. Compare the people in this story to those in the ads we looked at today. What similarities or differences did you notice?

\begin{tabular}{|l|l|}
\hline Components & Guiding Questions \\
\hline Questioning power & $\begin{array}{l}\text { Can girls and boys play with this toy? Which ad shows the } \\
\text { most powerful people? Why? Who was the most powerful } \\
\text { person in the book? Why? }\end{array}$ \\
\hline Collaborative discussion & $\begin{array}{l}\text { Four events: } \\
\text { After print ad, after "boy" Nerf ad, after "girl" Nerf ad, } \\
\text { after book }\end{array}$ \\
\hline Identity enactment or change & $\begin{array}{l}\text { Are any of the people in the ad like you? Which one(s)? } \\
\text { Why? Which ad shows people that are more like you? Why? }\end{array}$ \\
\hline Reading/viewing of popular media & $\begin{array}{l}\text { What is this ad trying to sell? Who is the target audience? } \\
\text { What did you think about the clips/book? Did you think } \\
\text { they were good or bad? Why? How did they make you } \\
\text { feel? Which is the best ad? Why? Compare the people in } \\
\text { this story to those in the ads we looked at today. What } \\
\text { similarities or differences did you notice? }\end{array}$ \\
\hline
\end{tabular}

